Retraction

\title{
Retracted: Influence of Al Content on Degradation Behavior of Cu-Doped Mg-Al Alloys for Drill-Free Plugging Applications
}

\author{
Advances in Materials Science and Engineering \\ Received 19 November 2021; Accepted 19 November 2021; Published 24 December 2021 \\ Copyright $\odot 2021$ Advances in Materials Science and Engineering. This is an open access article distributed under the Creative \\ Commons Attribution License, which permits unrestricted use, distribution, and reproduction in any medium, provided the \\ original work is properly cited.
}

Advances in Materials Science and Engineering has retracted the article titled "Influence of $\mathrm{Al}$ Content on Degradation Behavior of Cu-Doped Mg-Al Alloys for Drill-Free Plugging Applications" [1] due to concerns that appropriate permissions were not obtained for the publication of the data. The journal was contacted by a contributor to the data presented in the article, who raised concerns that key contributors were not listed as authors and were not consulted prior to the submission of the paper. The corresponding author contacted the journal separately to request the retraction of the article due to these concerns. Both parties additionally raised concerns with the reliability of the data, and the article is being retracted with the agreement of the authors and the editorial board.

\section{References}

[1] L. Kang, Y. Shi, X. Luo, and B. Liu, "Influence of Al Content on Degradation Behavior of Cu-Doped Mg-Al Alloys for DrillFree Plugging Applications," Advances in Materials Science and Engineering, vol. 2020, Article ID 8898669, 9 pages, 2020. 


\title{
Influence of Al Content on Degradation Behavior of Cu-Doped Mg-Al Alloys for Drill-Free Plugging Applications
}

\author{
Li Kang, Yixuan Shi, Xiaoping Luo (iD, and Baosheng Liu \\ Taiyuan University of Science and Technology, Taiyuan 030024, Shanxi, China \\ Correspondence should be addressed to Xiaoping Luo; lxpsyx@126.com
}

Received 28 August 2020; Revised 29 October 2020; Accepted 3 November 2020; Published 12 November 2020

Academic Editor: Gianfranco Carotenuto

Copyright (c) 2020 Li Kang et al. This is an open access article distributed under the Creative Commons Attribution License, which permits unrestricted use, distribution, and reproduction in any medium, provided the original work is properly cited.

\begin{abstract}
Herein, we report low-cost and rare-earth-free $\mathrm{Cu}$-doped $\mathrm{Mg}$ - $\mathrm{Al}$ alloys for drill-free plugging applications and present the influence of Al content on degradation behavior. The phase composition and microstructure of fabricated alloys were characterized by using a scanning electron microscope (SEM) and X-ray diffractometer (XRD). Also, degradation properties were investigated using hydrogen evolution tests and the electrochemical measurements. The results reveal that the $\mathrm{Al}$ content is directly related to the proportion of secondary phases, such as $\mathrm{Mg}_{2} \mathrm{Cu}, \mathrm{Mg}_{17} \mathrm{Al}_{12}$, and $\mathrm{MgAlCu}$. Moreover, the $\mathrm{Mg}_{17} \mathrm{Al}_{12}$ and $\mathrm{MgAlCu}$ phases are distributed at $\alpha$-Mg grain boundaries, whereas the $\mathrm{MgAlCu}$ phase is distributed within the $\mathrm{Mg}$ matrix. Acceleration of degradation rate is found due to microgalvanic corrosion in $\mathrm{Mg}$-xAl-2Cu (in wt. $\%$, named as $\mathrm{ACx} 2, x=0,3,5$, and 9) alloys. In this regard, $\mathrm{Mg}_{2} \mathrm{Cu}, \mathrm{Mg}_{17} \mathrm{Al}_{12}$, and $\mathrm{MgAlCu}$ phases act as a microgalvanic cathode against anodic magnesium matrixes. As such, the degradation rate of $\mathrm{ACx} 2$ alloys in $3.5 \% \mathrm{NaCl}$ solution is ranked from $\mathrm{AC} 02, \mathrm{AC} 32$, AC52, to AC92. In this context, the AC02 alloy shows the fastest degradation rate, 46 times higher than the AC92 alloy. This may provide a practical solution to develop good alternatives for drill-free plugging materials.
\end{abstract}

\section{Introduction}

The increasing demand for lightweight materials in aerospace, transport, and $3 \mathrm{C}$ industries has stimulated rapid development and utilization of Mg-based structural alloys due to their low density and high specific strength [1-3]. In particular, $\mathrm{Mg}$ - $\mathrm{Al}$ alloys are promising candidates for a wide range of applications because of their cost-effectiveness and superior mechanical properties. However, the rapid degradation of $\mathrm{Mg}-\mathrm{Al}$ alloys poses severe safety threats and hinders their practical utilization. One should note that Mgbased alloys rapidly degrade in aqueous electrolytes due to the high electronegative potential of $\mathrm{Mg}(-2.37 \mathrm{vs.} \mathrm{SHE).} \mathrm{In}$ general, $\mathrm{Fe}, \mathrm{Ni}$, and $\mathrm{Cu}$ exist as impurities in $\mathrm{Mg}$-based alloys, which act as highly polarized local cathodes with respect to $\mathrm{Mg}$ and accelerate the degradation rate [4]. Moreover, a low Pilling-Bedworth (PB) ratio of $\mathrm{MgO} / \mathrm{Mg}$ (0.81) leads to the formation of a loose oxide/hydroxide film on the surface, which increases the degradation rate [4-6].

Nevertheless, the high degradation rate of Mg-based alloys can be useful for some applications. For instance, degradable $\mathrm{Mg}$ is utilized as a sacrificial anode to protect the cathode. Moreover, degradable Mg-based bioimplants are promising candidates for biological applications from the viewpoints of cost and pain relief [7-12].

Recently, the infinite-stage fracturing of sliding sleeve in a horizontal well has become a hot research topic in the development of low-permeability oil and gas resources [13-15]. The bridge plug, as one of the key components in infinite-stage fracturing techniques, must be strong enough to bear the working pressure of $70 \mathrm{MPa}$ and withstand the operating temperature of $120^{\circ} \mathrm{C}$. However, the conventional plugging materials, such as polymers, aluminum alloys, and mild steel, cannot meet the practical requirements due to their low degradability rate in fracture liquor. Hence, the milling or drilling of bridge plug is required to dredge the pipeline after fracturing, resulting in complex operations and additional costs. Therefore, drill-free bridge plugs made of degradable materials with a high degradation rate are promising options to make the drill-out process economic and highly efficient. Hence, the conventional $\mathrm{Mg}$ - $\mathrm{Al}$ alloys are highly promising candidates for drill-free bridge plugs 
because the strength of $\mathrm{Mg}$-Al alloys (usually more than $150 \mathrm{MPa}$ ) is far greater than the bridge plug can handle. In addition, the softening temperature of grain boundary $\mathrm{Mg}_{17} \mathrm{Al}_{12}$ phase is $\sim 150^{\circ} \mathrm{C}$. Moreover, a small amount of copper can accelerate the degradation process and improve the heat resistance of Mg-based alloy. Hence, the presence of $\mathrm{Cu}$, as an impurity, exploits the superior mechanical properties and inferior degradation rate of $\mathrm{Mg}$ - $\mathrm{Al}$ alloy, making it a promising material for drill-free bridge plugs.

Herein, a novel series of ACx2 ( $x=0,3,5$, and 9) alloys was prepared by varying the $\mathrm{Al}$ content to tune the degradation rate. The influence of $\mathrm{Al}$ content on microstructure and degradation rate was characterized by using a combination of immersion tests and electrochemical methods. The results of this work can provide a novel strategy for the development of Mg-based alloys for drill-free bridge plugs.

\section{Experimental}

2.1. Materials. The chemical compositions of $\mathrm{ACx} 2$ alloys are listed in Table 1. As-cast alloys were produced by mixing pure $\mathrm{Mg}$ (99.9 wt.\%), Al (99.9 wt.\%), and copper (99.9 wt.\%) in an electrical furnace using a mild steel crucible. The raw materials were melted under an argon protective atmosphere at $760^{\circ} \mathrm{C}$ for $20 \mathrm{~min}$. The fusing fluid was stirred for $3 \mathrm{~min}$, followed by stabilization for $15 \mathrm{~min}$. The melted alloys were poured into a stainless-steel mold at $700^{\circ} \mathrm{C}$ and, then, cooled down to the ambient temperature. The casted ingots were cut for microstructural observations and degradation tests after homogenization at $400^{\circ} \mathrm{C}$ for $8 \mathrm{~h}$.

2.2. Material Characterization. The microstructure and elemental composition were analyzed by using an SEM (Hitachi S-4800) and energy dispersive spectrometer (EDS). The phase constitutions were analyzed using an XRD (Rigaku D/MAX-2500PC), using $\mathrm{Cu} \mathrm{Ka}$ radiation with the sample tilt angle ranging from $20^{\circ}$ to $85^{\circ}$, voltage $40 \mathrm{kV}$, current $40 \mathrm{~mA}$, and scanning speed $4 \% \mathrm{~min}$. Prior to SEM observations, the specimen surface was prepared by mechanical grinding (2000 grit SiC paper) and polished with $0.5 \mathrm{~mm}$ alumina suspension, followed by washing with distilled water. Then, the surface was etched by using a mixed solution of 4 vol. \% nitric acid and ethyl alcohol.

2.3. Degradation Tests. The degradation behavior was investigated by hydrogen evolution and polarization measurements. The samples were ground, polished, and encapsulated in epoxy resin with an exposed surface of $1.0 \mathrm{~cm}^{2}$ and immersed in $3.5 \mathrm{wt} . \%$ sodium chloride solution at $25^{\circ} \mathrm{C}$ to $72 \mathrm{~h}$. The evolved hydrogen was collected, as illustrated in Figure 1. The experimental data were recorded every hour. After the test, the samples were rinsed using a mixture of $\mathrm{AgNO}_{3}(10 \mathrm{~g} / \mathrm{L})$ and $\mathrm{CrO}_{3}(200 \mathrm{~g} / \mathrm{L})$ to remove the degradation products. Then, the samples were ultrasonically cleaned for $5 \mathrm{~min}$ and dried with warm air flow.

Surface observation is another way to evaluate the degradation resistance of $\mathrm{Mg}$-based alloys. The surface and crosssectional degradation morphologies and microregional composition were investigated using an SEM and EDS. The degradation products were removed from the surface before SEM observations.

\subsection{Electrochemical Characterization. Electrochemical} measurements were carried out in a standard three-compartment cell. Initially, the sample was immersed in the electrolyte solution for $3 \mathrm{~min}$ to stabilize the open circuit potential (OCP). Then, the working electrode was scanned over the voltage range of $\pm 200 \mathrm{mV}$ (vs. OCP) at a scan rate of $1.0 \mathrm{mV} \cdot \mathrm{s}^{-1}$. The polarization curves were measured in 3.5 wt.\% $\mathrm{NaCl}$ solution at ambient temperature. The electrodes were ultrasonically cleaned in acetone and rinsed with deionized water before electrochemical measurements. The coated samples were embedded with epoxy resins, and only $1 \mathrm{~cm}^{2}$ area was exposed to the electrolyte. The Tafel extrapolation method was used to measure the degradation parameters, including degradation potential $\left(\mathrm{E}_{\mathrm{corr}}\right)$ and degradation current density $\left(\mathrm{I}_{\text {corr }}\right)$. Electrochemical impedance spectroscopy (EIS) was carried out at a small potential perturbation $(10 \mathrm{mV})$ around OCP. Three independent samples were characterized by using potentiodynamic polarization and EIS to ensure the reproducibility of experimental data.

\section{Results and Discussion}

3.1. Microstructure and Phase Identification. SEM images, EDS images, and XRD patterns of the ACx2 alloys are shown in Figure 2. The AC02 alloy is mainly composed of the Mg matrix and few secondary phases, where white-colored $\mathrm{Mg} 2 \mathrm{Cu}$ particles are distributed in the matrix grains (Figure 2(a)). The presence of $\mathrm{Mg} 17 \mathrm{Al} 12$ and $\mathrm{MgAlCu}$ phases is confirmed in Al-containing alloys (Figures 2(b)$2(d)$ ), showing a lamellar interphase distribution at the crystal boundary with $\alpha-\mathrm{Mg}$. This was confirmed by the XRD results shown in Figure 2(h)

The precipitated $\mathrm{Mg} 17 \mathrm{Al} 12$ and $\mathrm{MgAlCu}$ phases are connected and distributed along the grain boundary, exhibiting continuous mesh morphology. Thus, the $\alpha-\mathrm{Mg}$ matrix regions are separated from each other, showing the characteristics of island distribution in the AC92 alloy (Figure 2(d)). Moreover, a part of $\mathrm{Mg} 17 \mathrm{Al} 12$ phase exhibits a lamellar shape and a small amount is observed inside the $\mathrm{Mg}$ matrix, which can be ascribed to the precipitation of $\mathrm{Mg}$ during the solidification process and the formation of Mg17Al12 phase in Al-rich solution. The face scanning results of corresponding positions in Figure 2(d) are shown in Figures 2(e)-2(g)). The elemental analyses reveal that $\mathrm{Cu}$ mainly exists in the three-phase eutectic form, where $\mathrm{Cu}$ enriched secondary phases consist of $\mathrm{Mg}, \mathrm{Al}$, and $\mathrm{Cu}$ elements. However, the presence of dual eutectic in only $\mathrm{Mg}$ matrix is rare. Because of the low solid solubility of $\mathrm{Cu}$ in $\mathrm{Mg}, \mathrm{Mg} 2 \mathrm{Cu}$ intermediate compounds are formed in the AC02 alloy. As the formation energy of $\mathrm{Mg} 2 \mathrm{Cu}$ phase is higher than that of $\mathrm{MgAlCu}$ phase, the $\mathrm{Mg} 2 \mathrm{Cu}$ phase is replaced by the $\mathrm{MgAlCu}$ phase and the Mg17Al12 phase is formed in Al-containing alloy. 
TABLE 1: Nominal chemical compositions of studied alloys (wt.\%).

\begin{tabular}{lccc}
\hline Alloys & $\mathrm{Cu}$ & $\mathrm{Al}$ & $\mathrm{Mg}$ \\
\hline AC02 & 2.0 & 0 & $\mathrm{Bal}$ \\
AC32 & 2.0 & 3.0 & $\mathrm{Bal}$ \\
AC52 & 2.0 & 5.0 & $\mathrm{Bal}$ \\
AC92 & 2.0 & 9.0 & $\mathrm{Bal}$ \\
\hline
\end{tabular}

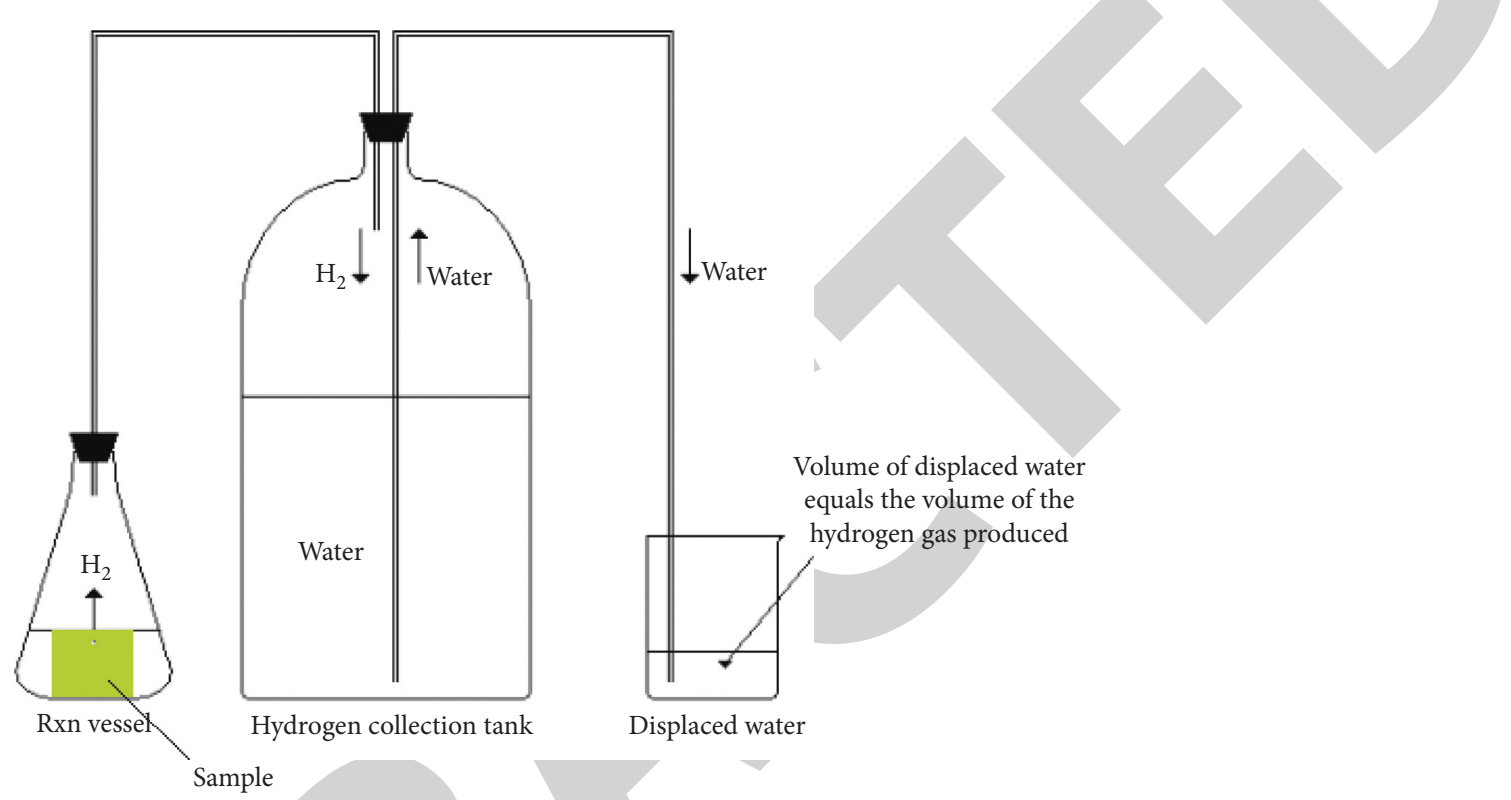

FIGURE 1: Schematic illustration of degradation rate measurement by collecting the volume of hydrogen.

3.2. Immersion Test and Degradation Morphology. The hydrogen evolution curves and immersion time of ACx2 alloys in 3.5 wt. $\% \mathrm{NaCl}$ solution are presented in Figure 3. It has been reported that the dissolution of one magnesium atom generates one hydrogen molecule. Hence, the weight loss of $\mathrm{Mg}$ alloy can be estimated from the volume of evolved hydrogen. The studied alloys exhibited an appreciable hydrogen release and the total volume of evolved hydrogen increased with increasing immersion time, which indicates that the degradation is accelerated with increasing immersion time. For instance, the Al-free AC02 alloy exhibited evolved hydrogen volumes of $127 \mathrm{~mL}$ and $1440 \mathrm{~mL}$ after being immersed for $10 \mathrm{~h}$ and $72 \mathrm{~h}$, respectively. In contrast, the corresponding evolved hydrogen volumes dramatically dropped to $31 \mathrm{~mL}$ and $75 \mathrm{~mL}$ for the AC92 alloy. Overall, the total volume of evolved hydrogen followed a decreasing order: $\mathrm{AC02}>\mathrm{AC} 32>\mathrm{AC} 52>\mathrm{AC} 92$.

The degradation morphology of the alloys was observed after being immersed for different times in $3.5 \% \mathrm{NaCl}$ solution, as shown in Figure 4 . The surface of degraded samples exhibited the presence of degradation products and muddy pits, indicating that the cracks cannot provide sufficient protection to the $\mathrm{Mg}$ matrix. Hence, the chloride ions can penetrate through the loose degradation product layer and cause continuous degradation. After being immersed in $3.5 \% \mathrm{NaCl}$ solution for $2 \mathrm{~h}$, the surface of $\mathrm{AC} 02$ alloy was completely degraded and exhibited bulk degradation products (Figure 4(a)). In the case of AC32 and
AC52 alloys, the degradation rate is significantly lower during the first $2 \mathrm{~h}$ and fewer surface degradation products were observed. However, when the immersion time was increased to $4 \mathrm{~h}$, the surface degradation increased but remained lower than that of the AC02 alloy (Figures 4(b) and 4(c)). The surface of AC52 alloy exhibited a fine needlelike degradation product, which is a common degradation product in $\mathrm{Mg}-\mathrm{Al}$ alloys.

As shown in Figure 4(d), the surface morphology of AC92 alloy, after being immersed for $13 \mathrm{~h}$, exhibited a dense and thin needle-like degradation product layer, which can be ascribed to the higher electrode potential of secondary phases than the $\alpha-\mathrm{Mg}$ matrix. Hence, the corrosion of neighboring $\alpha$-Mg matrix was accelerated, forming a dense layer of degradation product on the surface.

It should be noted that the degradation of Mg-alloys is limited by kinetics, which in turn depends on the alloy composition. The elemental composition of the degradation products on the AC92 surface is presented in Figure 4(e), showing the presence of $\mathrm{O}$ and $\mathrm{Mg}$ elements. It has been reported that these products are a mixture of $\mathrm{MgO}$ and $\mathrm{Mg}(\mathrm{OH})_{2}$. Moreover, the alloy contains small amounts of $\mathrm{Al}$ and $\mathrm{Cu}$, where $\mathrm{Cu}$ is mainly accumulated in protuberant regions and only a trace amount of $\mathrm{Cu}$ exists on the matrix surface. The protuberant $\mathrm{Cu}$ enrichment was confirmed to be the $\mathrm{MgAlCu}$ secondary phase, which plays a critical role in increased hydrogen evolution rate of the AC92 alloy because it acts as a microcathode. 

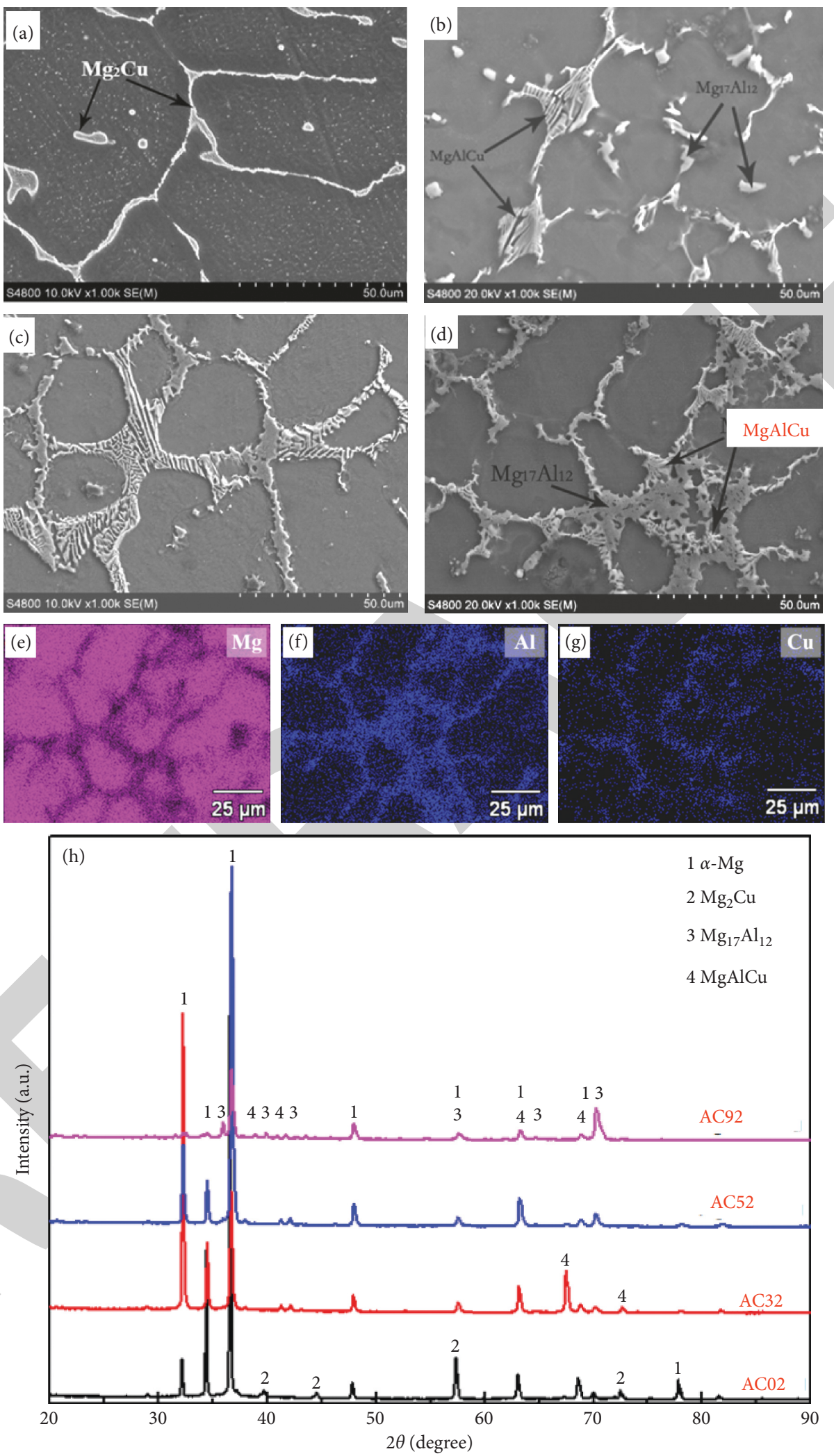

Figure 2: SEM and EDS images and XRD patterns of the ACx2 alloys. (a) AC02, (b) AC32, (c) AC52, (d) AC92, (e) Mg mapping, (f) Al mapping, (g) Cu mapping, and (h) XRD patterns. 


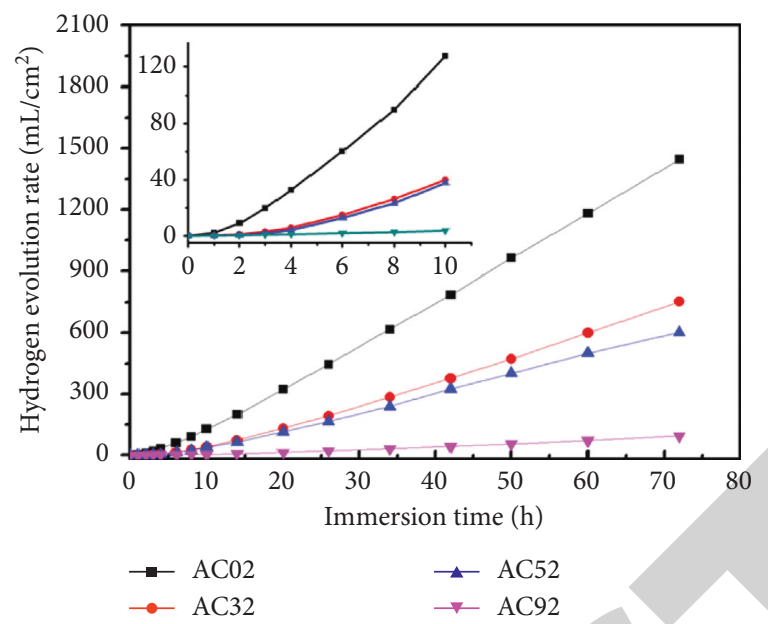

FIgURE 3: Relationship between hydrogen evolution rate and immersion time of the as-cast ACx2 alloy immersed in $3.5 \% \mathrm{NaCl}$ solution for $72 \mathrm{~h}$.
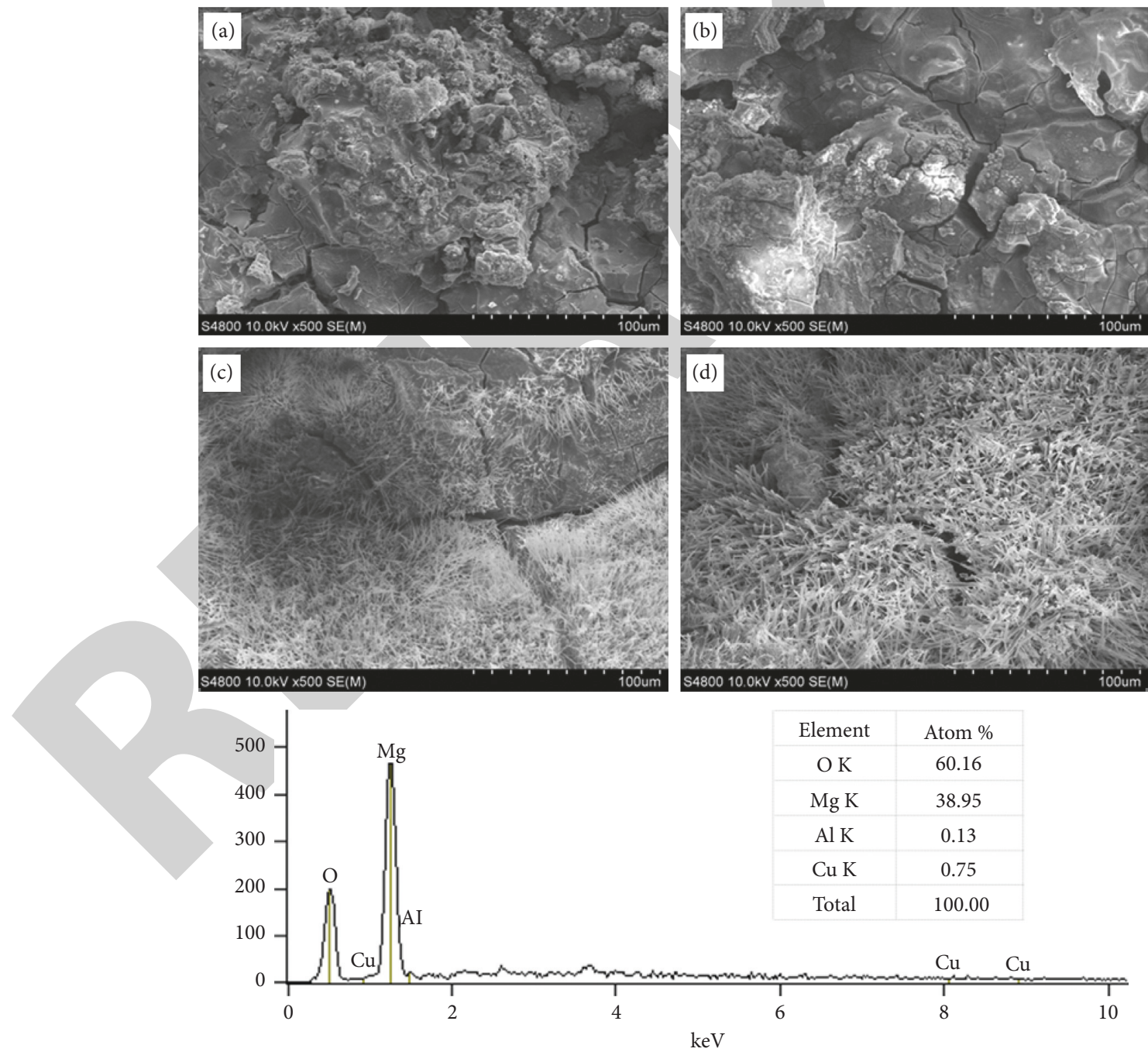

(e)

Figure 4: Surface SEM images of the as-cast (a) AC02 alloy immersed for $2 \mathrm{~h}$, (b) AC32 alloy immersed for 4 h, (c) AC52 alloy immersed for $4 \mathrm{~h}$, and (d) AC92 alloy immersed for $13 \mathrm{~h}$ in $3.5 \% \mathrm{NaCl}$ solution. (e) EDS analysis of the degradation products on the surface of as-cast AC92. 

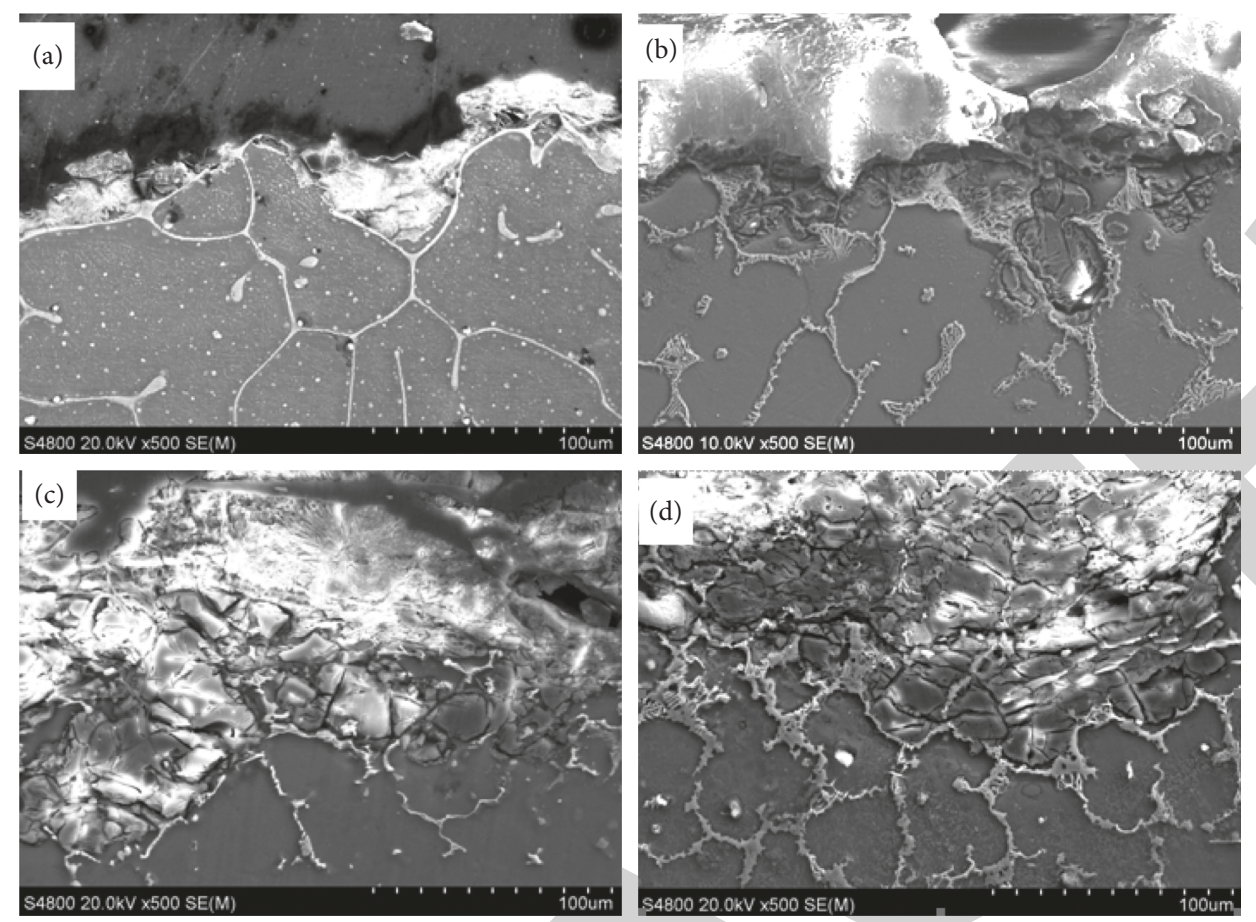

Figure 5: Cross-sectional SEM images of the as-cast (a) AC02 alloy immersed for $2 \mathrm{~h}$, (b) AC32 alloy immersed for $4 \mathrm{~h}$, (c) AC52 alloy immersed for $4 \mathrm{~h}$, and (d) AC92 alloy immersed for $13 \mathrm{~h}$ in $3.5 \% \mathrm{NaCl}$ solution.

Moreover, the interior of the alloy surface did not exhibit significant deterioration. For instance, the cross-sectional SEM images of ACx2 alloys, immersed in $\mathrm{NaCl}$ solution for $4 \mathrm{~h}$, did not exhibit any signs of interior deterioration (Figure 5). One should note that the alloy substrate experienced different degrees of degradation from the surface.

As electrode potential of the fine-grained $\mathrm{Mg}_{2} \mathrm{Cu}$ phase is higher than that of $\alpha-\mathrm{Mg}$ substrate, the $\alpha-\mathrm{Mg}$ acted as an anode and rapidly dissolved to form a loose degradation layer, which did not accumulate on the substrate surface (Figure 5(a)). Therefore, a large number of degradation products fell off from the alloy surface and settled at the bottom. Once the degradation products around the $\mathrm{Mg}_{2} \mathrm{Cu}$ phase fell off and dissolved, the $\mathrm{Mg}_{2} \mathrm{Cu}$ phase experiences fracture dissolution due to the absence of surrounding supports. The cross-sectional morphologies of AC32 and AC52 alloys are presented in Figures 5(b) and 5(c), showing the presence of $\mathrm{Mg}_{17} \mathrm{Al}_{12}$ and $\mathrm{MgAlCu}$ phases. Moreover, the degradation of $\alpha-\mathrm{Mg}$ substrate continued due to the potential difference between substrate and intermediate phases. In addition, once the matrix was degraded, the dissolved Al formed a passivation film, which also acted as a protective layer and hindered further degradation. In the case of AC92 alloy, a dense layer of $\mathrm{Mg}_{17} \mathrm{Al}_{12}$ phase was formed on the alloy surface, which provided excellent protection against $\alpha$-Mg substrate (Figure 5(d)).

Figure 6 shows SEM images of as-cast ACx2 alloys after removing the degradation products with $\mathrm{Cr}_{2} \mathrm{O}_{3} / \mathrm{AgNO}_{3}$ solutions. It can be clearly observed that the $\mathrm{Mg}$ matrix suffered severe degradation and some residual fine strips of $\mathrm{MgCu}_{2}$ phases were found on the surface of AC02 alloy (Figure 6(a)). In the case of AC32 alloy, the amount of secondary phase increased after the addition of $\mathrm{Al}$, which altered the cathode/anode area ratio (Figure 6(b)). Hence, the secondary phase formed a microelectric couple and accelerated the degradation rate. However, a passivation film was also formed which protected the matrix from further degradation. In the case of AC52 alloy, the area of microelectric couple increased due to the higher content of $\mathrm{Al}$, which resulted in further formation of the passivation film of AC52 alloy (Figure 6(c)). Figure 6(d) shows that the amount of secondary phase rapidly increased in the AC92 alloy due to content of $\mathrm{Al}$. Moreover, the laminated $\mathrm{MgAlCu}$ phase and reticulated $\mathrm{Mg}_{17} \mathrm{Al}_{12}$ phase were interconnected and distributed on the surface of the matrix to decrease the degradation rate of AC92 alloy.

3.3. Electrochemical Characterization. Furthermore, the electrochemical polarization curves of ACx2 alloys in 3.5 wt.\% $\mathrm{NaCl}$ electrolyte were recorded to further investigate the degradation properties (Figure 7). Figure 7 shows that the polarization curves of $\mathrm{ACx} 2$ alloys were similar in shape but asymmetric with respect to the composition. The potential of AC92 alloy was shifted towards the right with increasing $\mathrm{Al}$ content, whereas the anodic and cathodic current densities decreased due to the formation of second phase. Also, the cathodic slope was higher than the anodic slope. From the thermodynamics viewpoint, the polarization curve of AC92 alloy exhibits the least degradation tendency. On the other hand, the anodic current density of AC32 and AC52 alloys was found to be similar to that of AC02 alloy. Moreover, the cathodic current density of AC32 and AC52 alloys was lower than that of AC02 alloy. Hence, AC32 and 

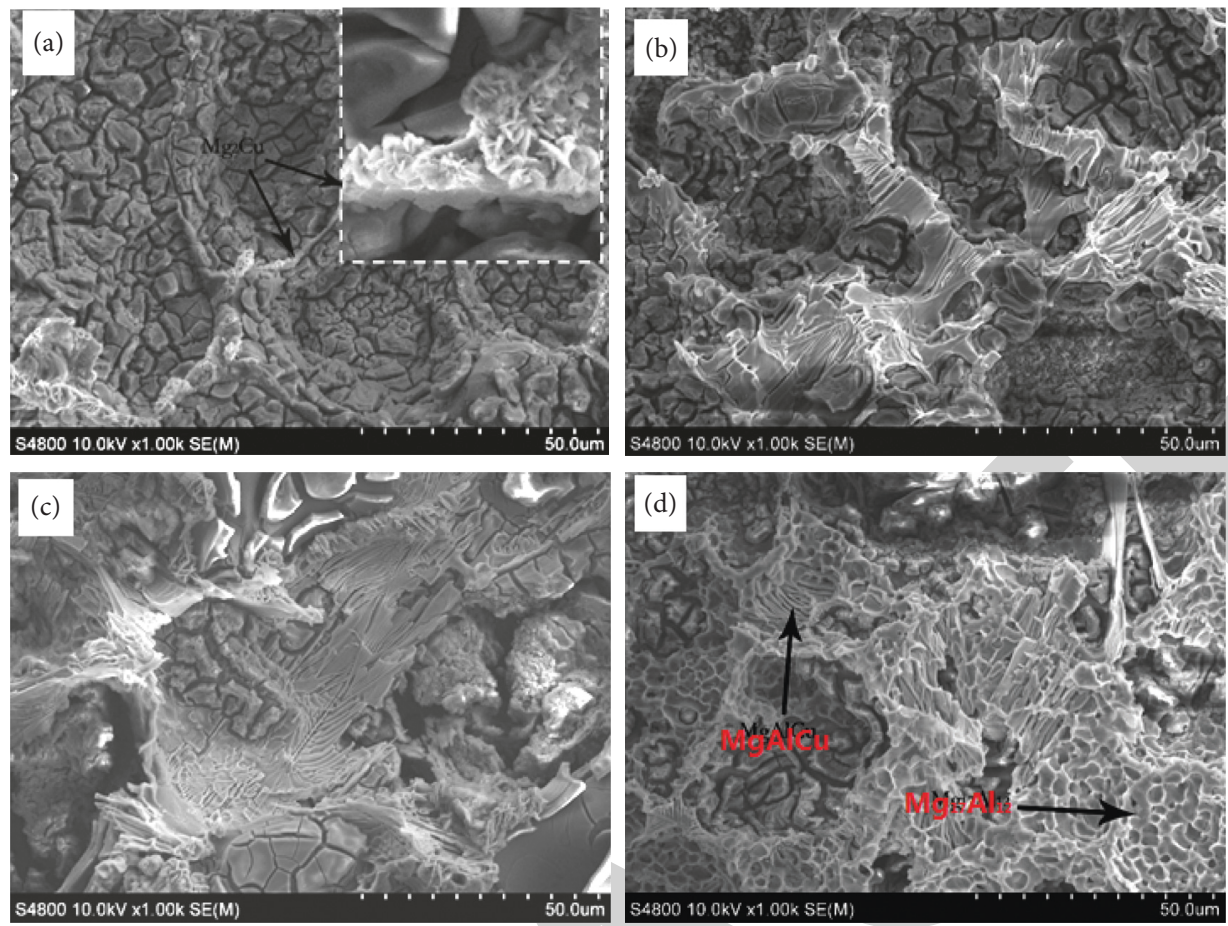

FIGURE 6: SEM micrographs after removing the degradation products: (a) AC02 alloy immersed for $2 \mathrm{~h}$, (b) AC32 alloy immersed for 4 h, (c) AC52 alloy immersed for $4 \mathrm{~h}$, and (d) AC92 alloy immersed for $13 \mathrm{~h}$ in $3.5 \% \mathrm{NaCl}$ solution.

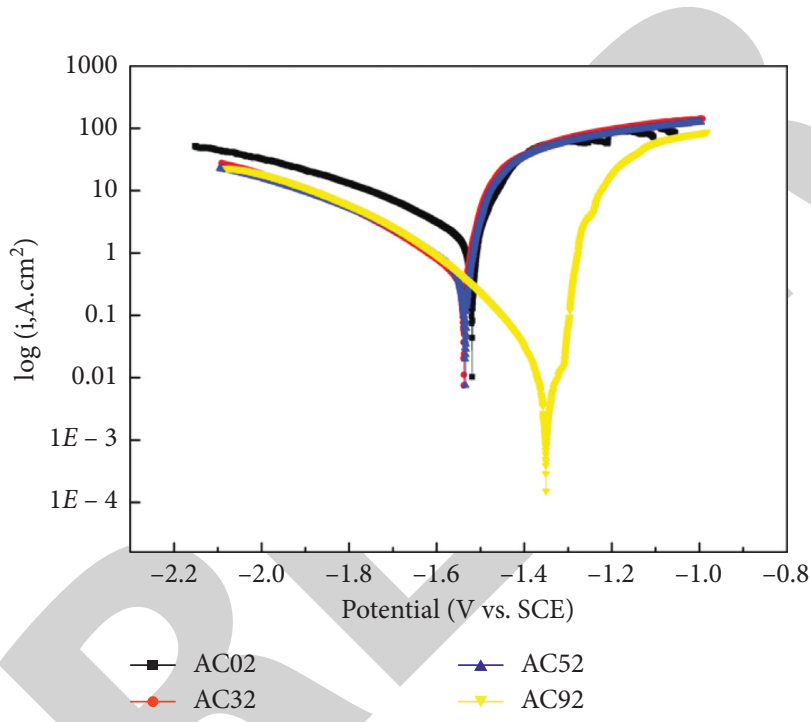

FIgURE 7: Potentiodynamic polarization curves of the as-cast $\mathrm{AC} \times 2$ alloys immersed in $3.5 \% \mathrm{NaCl}$ solution.

AC52 alloys exhibited severe degradation and experienced higher degradation rate. The decrease in anodic current density indicates that the addition of $\mathrm{Al}$ hinders the degradation of $\mathrm{Mg}$ anode. However, the presence of $\mathrm{Al}$ inhibits the hydrogen evolution reaction at cathode, yielding similar cathodic kinetics.

The degradation potential $\left(E_{\text {corr }}\right)$ and degradation current density $\left(I_{\text {corr }}\right)$ are derived by using the Tafel extrapolation method (Table 2). It can be readily observed that the addition of Al initially shifted the potential towards the
TABLE 2: Electrochemical parameter values of the alloys from Tafel curves.

\begin{tabular}{lcc}
\hline Alloys & $E_{\text {corr }}\left(V_{\text {SCE }}\right)$ & $I_{\text {corr }}\left(A / \mathrm{cm}^{2}\right)$ \\
\hline AC02 & -1.518 & $46.03 \times 10^{-5}$ \\
AC32 & -1.539 & $2.55 \times 10^{-5}$ \\
AC52 & -1.534 & $2.95 \times 10^{-5}$ \\
AC92 & -1.351 & $1.01 \times 10^{-5}$ \\
\hline
\end{tabular}

negative direction. AC02, AC32, and AC52 alloys exhibited the $E_{\text {corr }}$ values of $-1.518 \mathrm{~V},-1.539 \mathrm{~V}$, and $-1.534 \mathrm{~V}$, respectively. Hence, the $\mathrm{Al}$ content of 3-5 wt.\% increased the degradation rate of alloys. However, at the Al content of 9 wt.\%, the AC92 alloy exhibited a degradation potential of $-1.351 \mathrm{~V}$, indicating the lowest degradation rate, which is consistent with the polarization curves and morphological observations.

In particular, the AC92 alloy exhibited the lowest $I_{\text {corr }}$ value of $1.01 \times 10^{-5} \mathrm{~A} \cdot \mathrm{cm}^{-2}$, whereas the AC02 alloy exhibited a 46 times higher current density of $46 \times 10^{-5} \mathrm{~A} \cdot \mathrm{cm}^{-2}$. Hence, the degradation rate of ACx 2 alloys is decreased by $\mathrm{Al}$ addition, which indicates that the intermetallics are cathodically polarized and remain protected at the expense of matrix dissolution.

The Nyquist plots of as-cast alloys are shown in Figure 8. The Nyquist plots consist of a large high-frequency capacitance loop and a low-frequency inductance loop, where the former corresponds to the degradation product layer on the surface and the latter indicates the attack on $\mathrm{Mg}$ substrate. The radius of the high-frequency capacitance loop reflects the charge transfer resistance of the active degradation electrode. The higher charge transfer resistance indicates a 




Figure 8: Nyquist plots of the as-cast ACx2 alloys in $3.5 \% \mathrm{NaCl}$ solution.

higher barrier to the alloy dissolution in $\mathrm{NaCl}$ solution and, in turn, a lower degradation rate. The AC92 alloy exhibited the highest arc radius, corresponding to a minimum degradation rate, whereas the AC02 alloy exhibited the smallest charge transfer resistance, corresponding to the maximum degradation rate. Consequently, the tested alloys exhibited a decreasing degradation rate with increasing $\mathrm{Al}$ content in the given sequence: AC02 > AC32 > AC52 > AC92. Hence, both the immersion test and electrochemical characterization revealed a similar degradation behavior.

\section{Conclusions}

To explore alternative materials for drill-free plugging in the oil and gas industry, the influence of $\mathrm{Al}$ addition on the degradation behavior of $\mathrm{Cu}$-doped $\mathrm{Mg}$-Al alloys was studied herein. The following conclusions can be drawn from the current results:

(1) ACx2 $(x=0,3,5$, and 9 wt.\%) alloys consisted of $\alpha-\mathrm{Mg}, \mathrm{Mg}_{2} \mathrm{Cu}, \mathrm{Mg}_{17} \mathrm{Al}_{12}$, and $\mathrm{MgAlCu}$ phases. The addition of $\mathrm{Al}$ led to the formation of $\mathrm{MgAlCu}$ and $\mathrm{Mg}_{17} \mathrm{Al}_{12}$ phases and the disappearance of the $\mathrm{Mg}_{2} \mathrm{Cu}$ phase. The content of $\mathrm{Mg}_{17} \mathrm{Al}_{12}$ and $\mathrm{MgAlCu}$ phases increased with an increase in $\mathrm{Al}$ content. The $\mathrm{Mg}_{17} \mathrm{Al}_{12}$ phase was continuously distributed at $\alpha-\mathrm{Mg}$ grain boundaries, and the $\mathrm{MgAlCu}$ phase was distributed within the matrix. The $\mathrm{Mg}_{17} \mathrm{Al}_{12}$ and $\mathrm{MgAlCu}$ phases acted as cathodes against the $\alpha-\mathrm{Mg}$ matrix and formed microgalvanic electric cells, reducing the degradation rate of $\mathrm{ACx} 2$ alloys.

(2) Vigorous H2 liberation, accompanied by pitting, dominated the degradation of the ACx2 alloys after being immersed in $3.5 \% \mathrm{NaCl}$ solution for $72 \mathrm{~h}$. The AC02 alloy exhibited the maximum volume of evolved $\mathrm{H} 2(1440 \mathrm{~mL})$, whereas the AC92 alloy exhibited the minimum volume of evolved $\mathrm{H} 2$ $(75 \mathrm{~mL})$. The degradation rate of ACx2 alloys in 3.5 wt.\% $\mathrm{NaCl}$ solution can be ranked as follows: $\mathrm{AC} 02>\mathrm{AC} 32>\mathrm{AC} 52>\mathrm{AC} 92$. This sequence was also confirmed by electrochemical measurements. The high degradation rate of $\mathrm{Cu}$-doped $\mathrm{Mg}$-Al alloys makes them promising candidates for drill-free plugging applications.

\section{Data Availability}

The data used to support the findings of this study are included within the article.

\section{Conflicts of Interest}

The authors declare that there are no conflicts of interest regarding the publication of this paper.

\section{Acknowledgments}

This study was financially supported by the Natural Science Foundation of Shanxi Province, China (No. 201901D111272).

\section{References}

[1] A. A. Luo, "8-applications: aerospace, automotive and other structural applications of magnesium," in Proceedings of the Fundamentals of Magnesium Alloy Metallurgy, pp. 266-316, Woodhead Publishing, August 2013, https://www.google. $\mathrm{com} /$ search?q=Cambridge\&stick=H4sIAAAAAAAAAOPgELSz9U3MKmqrMhOU-IAsS3NLYq0jDLKrfST83NyUpNLM vPz9POL0hPzMqsSQZxiq4zUxJTC0sSiktSiYoWc_GSw8CJ WTufE3KSizJT01B2sjAD_195_WwAAAA\&sa=X\&ved=2ahU KEwiigf-Cj-7sAhXzmeYKHQMpDGIQmxMoAjATegQIDhAE.

[2] H. Westengen and H. M. M. A. Rashed, "Magnesium: alloying," in Proceedings of the Reference Module in Materials Science and Materials Engineering, Elsevier, Amsterdam, The Netherlands, January 2016.

[3] Engineering-Civil and Mechanical Engineering, "Studies in the area of civil and mechanical engineering reported from wroclaw university of science \& technology (the potential of slm technology for processing magnesium alloys in aerospace industry)," Chemicals \& Chemistry, vol. 20, no. 1, 2020.

[4] G. L. Song and A. Atrens, "Corrosion mechanisms of magnesium alloys," Advanced Engineering Materials, vol. 1, p. 11, 2010.

[5] Y. Xue, X. Pang, B. Jiang, J. Hamid, and D. Wang, "Characterization of the corrosion performances of as-cast $\mathrm{Mg}-\mathrm{Al}$ and $\mathrm{Mg}-\mathrm{Zn}$ magnesium alloys with microarc oxidation coatings," Materials and Corrosion, vol. 71, no. 6, 2020.

[6] L. Chen, Z. Wu, D.-H. Xiao, Z.-W. Geng, and P.-F. Zhou, "Effects of copper on the microstructure and properties of Mg-17Al-3Zn alloys," Materials and Corrosion, vol. 66, no. 10, pp. 1159-1168, 2015.

[7] K. Gusieva, C. H. J. Davies, J. R. Scully, and N. Birbilis, "Corrosion of magnesium alloys: the role of alloying," International Materials Reviews, vol. 60, no. 3, pp. 169-194, 2015.

[8] G. L. Song and A. Atrens, "Corrosion mechanisms of magnesium alloys," Advanced Engineering Materials, vol. 1, no. 1, pp. 11-33, 1999. 
[9] N. Wang, R. Wang, C. Peng, B. Peng, Y. Feng, and C. Hu, "Discharge behaviour of Mg-Al-Pb and Mg-Al-Pb-In alloys as anodes for Mg-air battery," Electrochimica Acta, vol. 149, pp. 193-205, 2016.

[10] Z. Han and L. Huang, "A review on ignition mechanisms and characteristics of magnesium alloys," Journal of Magnesium and Alloys, vol. 16, no. 5, 2020.

[11] Metals Research, "Studies in the area of metals research reported from amrita vishwa vidyapeetham (research and development in magnesium alloys for industrial and biomedical applications: a review)," Chemicals \& Chemistry, vol. 20, 2020.

[12] R. Chalisgaonkar, "Insight in applications, manufacturing and corrosion behaviour of magnesium and its alloys-a review," Materials Today: Proceedings, vol. 21, pp. 1223-1228, 2020.

[13] D. R. Watson and D. G. Durst, "One-trip multistage completion technology for unconventional gas formations," Society of Petroleum Engineers, vol. 17-19, pp. 703-716, 2008.

[14] C. Franco, R. Solares, H. Marri, and H. Hussain, "The use of stagefrac new technology to complete and stimulate horizontal wells: field case," Society of Petroleum Engineers, vol. 19, pp. 441-450, 2008.

[15] D. Themig, "New technologies enhance efficiency of horizontal, multistage fracturing," Journal of Petroleum Technology, vol. 63, no. 4, pp. 52-55, 2011. 